\title{
An old but enduring argument
}

The age-old issue of "basic" versus "applied" research in agriculture (it has literally been with us for more than a century!) continues to crop up. In a recent instance, two groups examined the same research program and came up with opposite conclusions as to its significance.

On the one hand, a national advisory committee on agricultural policy expressed alarm and dismay over low-level allocation of money for basic agricultural research and gave such research the highest priority among nine areas recommended for increased support by the U.S. Department of Agriculture. At the same time, a respected trade publication in California expressed strong concern for what it terms a demoralizing shift to basic research, at the expense of production research, created by new USDA funding practices.

Such divergent viewpoints are not unique. They can be heard in the halls of academe as much as anywhere.

I share the view of many of my colleagues that it may not be productive even to argue the issue; that it may in fact be a mistake to try to categorize too neatly the different types of research we do. It would be far more useful to treat all phases of agricultural research as parts of a total program closely related and inseparable from the other parts.

Basic research is frequently described as what the faculty of a university does to satisfy its own intellectual curiosity - to acquire knowledge for its own sake. In this viewing frame, scientists in the Experiment Station or Extension are limited to the conduct of mission-oriented, applied research.

In reality, a good deal of what we call basic research is very strongly mission-oriented. It arises from the effort of someone trying to apply knowledge who runs up against a barrier and has to go back to fill in the gaps.

That is one of the great advantages of an agricultural scientist: he has an opportunity to be active in the full spectrum of research, from basic investigation through practical application. Our scientists are comfortable in this atmosphere and have been highly productive as a result. The capacity to conduct both basic and applied research is one of the great strengths of a Land-Grant institution.

If there is a distinction that can be drawn between types of agricultural research, it is probably in timing. Expec-

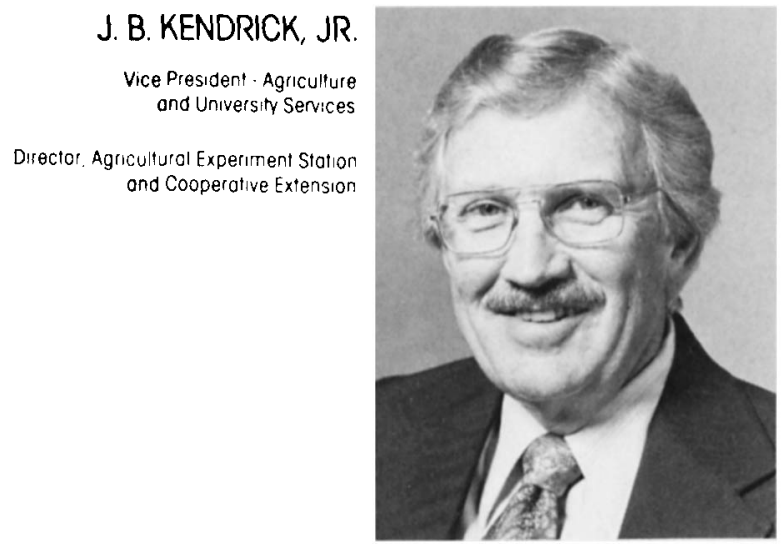

tations of output differ. In these pragmatic days, scientists engaged in applied research are expected to come up with tangible results in one, two or three years. The benefits of fundamental research may take years to materialize.

The bottom line of both types of research, however, is the same: Is it useful?

Most scientists would agree that a study of the process whereby some bacteria can fix atmospheric nitrogen or a study on the secrets of photosynthesis is basic research. Yet the implications for utility of the knowledge that may come out of either study are ever-present. The potential for applying new knowledge developed in this research is mind-boggling. At some point in time, virtually all bits of new knowledge find some application. It is a rare individual these days who is not aware of the possible implications of his work.

There is some feeling that our reservoir of knowledge about agriculture is getting low and that it is time we refill the reservoir so that we will have something to draw on in the future. There is fear that unless we maintain our investigations into the fundamental principles of food and fiber production, we will not be able to realize major breakthroughs in productivity.

The point may be valid, but we were talking about reaching the limit of our technological capacity 25 or 30 years ago. We have nevertheless continued to increase our output, not because of dramatic breakthroughs, but because of marginal improvements on a number of fronts: better management, better use of water and fertilizer, better seed, better pest and disease control, and so forth. I believe that will continue to be the pattern of our progress.

We now live in an era of applied research, where the emphasis is on instant results. And even though application of knowledge is the philosophic underpinning of the Land-Grant system, to pursue one aspect of research to the exclusion of another is a risky course.

Basic research is expensive, the results uncertain and often difficult to identify clearly. We may come up with dry wells. But fundamental investigations into the mysteries of plant and animal growth, into nutrition and into human behavior are part of a total research effort, just as in applied research. Without both, the circle is not complete. 